\title{
Formação do professor de geografia: um olhar para o pensamento geográfico
}

\author{
[ Teacher training of geography: a look at geographical thinking
}

\section{Andréa Rabelo Marcelino ${ }^{\mathrm{I}}$}

\section{Gildo Volpato ${ }^{2}$}

\begin{abstract}
RESUMO - Atualmente vivemos em tempos de constante transformação educacional, pensando e estudando possibilidades de melhoria da educação em todas as áreas do conhecimento. Para compreender o pensamento geográfico na formação do professor de geografia em dois cursos de licenciatura na modalidade a distância, pretendemos analisar as correntes de pensamento geográfico contidas nas DCNs de geografia e nos PPCs e identificar as correntes de pensamento geográfico contidas na matriz curricular dos cursos. A abordagem foi qualitativa e a técnica utilizada foi a análise documental dos cursos. A corrente de pensamento que mais foi identificada foi a crítica, evidenciando nos documentos a interação entre o espaço vivido e a sociedade, não sendo possível, no entanto, perceber no estudo como essa interação é organizada na modalidade a distância. • PALAVRASCHAVE • Educação; pensamento geográfico;
\end{abstract}

formação de professores. · ABSTRACT . We currently live in times of constant educational transformation, thinking and studying possibilities for an improvement in education in all areas of knowledge. In order to understand the geographic thinking in the formation of the geography teacher in two degree courses in the distance modality, we pretended to analyze the currents of geographic thinking contained in the geography DCNs and in the PPCs and identify the currents of geographic thought contained in the curriculum of the courses. The approach was qualitative and the technique used was the document analysis of the courses. The current of thought that was most identified was criticism, showing in the documents the interaction between the lived space and society, however, it is not possible to see in the study how this interaction is organized in the distance modality. · KEYWORDS · Education; geographic thinking; teacher training.

Recebido em 27 de julho de 2020

Aprovado em 2 de julho de $202 \mathrm{I}$

MARCELINO, Andréa Rabelo: VOLPATO, Gildo. Formação do professor de geografia: um olhar para o pensamento geográfico. Revista do Instituto de Estudos Brasileiros, Brasil, n. 79, p. 87-IO3, ago. 202I.

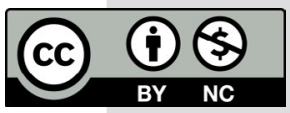

DOI: https://doi.org/Io.II6o6/issn.23I6-90IX.vii79p87-I03

I Universidade do Extremo Sul Catarinense (Unesc, Criciúma, SC, Brasil).

2 Universidade do Extremo Sul Catarinense (Unesc, Criciúma, SC, Brasil). 
Vivemos em um mundo globalizado, onde o desenvolvimento dos transportes e das comunicações passa a exigir um mundo cada vez mais unitário, porém situado em diferentes dimensões e espaços geográficos. Mundialmente, podemos dizer que existe uma única sociedade humana, porém com desigualdades e grande diversidade.

Assim como as demais áreas, a educação passa por uma fase de intensas reformulações, e com isso o ensino da disciplina de geografia deve ser repensado e reconstituído no espaço das instituições de ensino. Vesentini (20I3, p. 8) comenta que um dos grandes desafios para este novo século está pautado no "papel da escola na sociedade: as suas relações com a cidadania”. Frente às rápidas modificações e inovações em diferentes espaços, cabe a reflexão no sentido de quais as potencialidades que a escola deve desenvolver em seus alunos, que relações deve cultivar com os grupos da comunidade em que está inserida. E, para tal, torna-se importante conhecer os processos de formação de professores de geografia e as correntes de pensamento geográfico que embasam essa formação, pois são eles que irão atuar nas escolas.

As leituras realizadas fortaleceram a proposta de estudo apresentada, que partiu da seguinte problemática de pesquisa: qual a corrente de pensamento geográfico que embasa a formação do professor de geografia? Nesse sentido, o objetivo geral dessa pesquisa ${ }^{3}$ foi compreender as correntes de pensamento geográfico que embasam a formação do professor nos cursos de licenciatura em geografia na modalidade de ensino a distância.

Para alcançar o objetivo geral da pesquisa, foram definidos os seguintes objetivos específicos: a) analisar as correntes de pensamento geográfico contidas nas Diretrizes Curriculares Nacionais (DCNs) de geografia; b) verificar as correntes de pensamento geográfico que estão contidas nos projetos pedagógicos dos cursos de geografia; c) identificar as correntes de pensamento geográfico contidas na matriz curricular dos cursos.

Para encontrar possíveis respostas para esse problema, definimos como lócus da

3 Dessa pesquisa, resultou também o presente texto, que é uma versão modificada de capítulo da dissertação de mestrado O pensamento geográfico na formação do professor de geografia: um estudo em dois cursos de licenciatura (MARCELINO, 20I9). 
pesquisa duas instituições de ensino superior que possuem polos no município de Criciúma (SC) e ofertam o curso de geografia na modalidade a distância. A proposta de pesquisa nasceu da tentativa de entender a formação de ideias geográficas e a visão de mundo que lhe serve de base e sustentação para poder reconhecer, com maior clareza, a geografia que se aprende nessas instituições, pois se supõe que são elas que condicionam as correntes de pensamento geográfico que permeiam as escolas de ensino básico.

A pesquisa foi de abordagem qualitativa, que tomou como base a análise documental, priorizando os documentos como DCNs de geografia, o PPC e as matrizes curriculares dos cursos de licenciatura em geografia pesquisados.

A interpretação dos dados tomou como base os princípios da análise de conteúdo. De acordo com Bardin (2009), a análise de conteúdo segue primeiramente a pré-análise, na sequência, a exploração do material e, por fim, a interpretação e análise dos resultados obtidos.

A pesquisa foi desenvolvida com reflexões teóricas baseadas nos seguintes referenciais: Parâmetros Curriculares Nacionais (BRASIL, I997), Lei de Diretrizes e Bases da Educação Nacional (BRASIL, I996), Diretrizes Curriculares Nacionais (BRASIL, 200I); e nos seguintes autores: Andrade (I987), Callai (200I; 20I3), Moreira (I994; 20I0), Nogueira e Carneiro (20I3), Santos (I985; I986), Vesentini (2013), entre outros.

Parte-se da contextualização sobre o tema abordando questões históricas das correntes do pensamento geográfico bem como sobre o ensino de Geografia proposto nos documentos oficiais e na literatura didática brasileira. Em seguida apresentam-se os resultados da pesquisa realizada nos dois cursos de licenciatura em geografia.

\section{HISTÓRICO DAS CORRENTES DO PENSAMENTO GEOGRÁFICO}

Os conhecimentos geográficos vêm sendo aplicados desde os povos primitivos, e foram se ampliando à medida que a sociedade foi se desenvolvendo e se transformando.

Ferreira e Simões (I992) comentam que esses povos primitivos, mesmo sem dominar a escrita, registravam o conhecimento no interior das cavernas por meio de símbolos e desenhos, transmitindo seus conhecimentos de geração a geração. Nesse contexto, percebe-se o quanto esses povos possuíam ideias geográficas, ainda que não fosse um conhecimento acadêmico, mas um conhecimento do seu saber prático, saber da experiência vivenciada ao longo dos anos em interação com o meio físico e social.

Ferreira e Simões (I992, p. 26) definem a geografia como a ciência que vai estudar as "variações das distribuições espaciais dos fenômenos da superfície da Terra" e as relações da natureza com o ser humano. Segundo Pereira (2009), esse ramo da ciência surge entre os gregos, pois são os primeiros a registrar os conhecimentos relacionados à superfície terrestre.

Andrade (I987) salienta que os mesopotâmios aprenderam os ensinamentos sobre astronomia identificando as estrelas e alguns planetas. Foi esse povo que observou o movimento da revolução lunar em volta da Terra, estabelecendo a quantidade de dias em um ano e a organização dos dias da semana de acordo com as fases da Lua. 
Um estudo importante foi realizado por Dicearco e Eratóstenes (275 a.C.-I95 a.C.) com o intuito de estabelecer o tamanho do planeta Terra, medindo as latitudes. De acordo com Pereira (2009, p. 49), Eratóstenes, “diretor da biblioteca de Alexandria”, escreveu a primeira obra chamada de Geografia reescrita após 200 anos por Estrabão.

Andrade (I987, p. 24) comenta que, na obra, Estrabão relata os conhecimentos sobre o mundo de sua época a partir do registro de suas viagens, ficando conhecido como o "pai da geografia regional". O estudo de observações registradas a partir de viagens realizadas pela costa litorânea possibilitou a construção dos primeiros "périplos"4, que, mesmo sem as medidas corretas, sem escalas, já apresentavam os pontos de referências entre os portos da costa.

Segundo Pereira (2009) a população faz geografia há muito tempo, no entanto, faz sem saber. Havia duas tendências opostas ou complementares no conhecimento da época:

De um lado, os geômetras e os astrônomos; de outro, os viajantes, os curiosos, os historiadores e os políticos, que, sensíveis aos aspectos do quadro natural, das produções, dos povos e de seus costumes, refletem sobre as relações entre os diferentes territórios e as várias sociedades humanas. Os périplos, as conquistas, os contatos com o mundo bárbaro vão paulatinamente alargando o horizonte geográfico. (PEREIRA, 2009, p. 65).

Medeiros (20I0) destaca que o desenvolvimento das ciências, principalmente a Geografia, no espaço de tempo entre o século XVIII e XIX, e as descobertas científicas em função da expansão do capitalismo apresentaram fortes influências para a formação da Geografia Moderna.

Moraes (2002) afirma que a geografia, como ciência, teria sua origem a partir dos registros de Alexander Von Humboldt e de Carl Ritter. Esses dois pensadores - Humboldt e Ritter - são considerados os precursores da geografia moderna, e foi a partir da influência deles que se iniciou a geografia científica (MOREIRA, I994).

A geografia tradicional, também conhecida como geografia clássica, surge na Alemanha e na França no início do século XIX, estendendo-se para outros países. Os pensadores que levantaram a bandeira dessa corrente foram Alexander Von Humboldt e Carl Ritter. É nessa corrente de pensamento que emergem os primeiros conceitos de geografia e o seu objeto de estudo, pois, até então, a geografia era conhecida como uma ciência que estudava tudo que existia na superfície terrestre.

Souza et al. (2009, p. 3) afirmam que as primeiras definições sobre a geografia e o seu objeto de estudo não eram claras. Era considerada a disciplina "do tudo" ou "da superfície terrestre".

Durante esse período do século XIX, Andrade (I987, p. 50-5I) salienta que:

4 Périplos são mapas com itinerários de estudos de áreas litorâneas, dominadas pelos gregos. Tratava-se de documento manuscrito que registrava, em uma sequência, os portos e os pontos geográficos costeiros, com as distâncias aproximadas entre eles. 
[...] as desigualdades sociais tornaram-se tão fortes, tão marcantes que estudiosos da sociedade formularam teorias que contestavam os princípios justificadores do capitalismo em expansão. Essa contestação foi feita, a princípio, pelos socilialistas utópicos, que imaginavam sociedades mais justas, situadas em pontos de difícil acesso, como ilhas imaginárias, localizadas a grande distância; em seguida surgiram pensadores materialistas que, baseados na observação, na análise das estruturas sociais e na evolução da sociedade, criticaram estas estruturas e partiram para o desenvolvimento de uma metodologia de análise dialética, para a contestação da sociedade e a indicação de transformações sociais que deveriam ocorrer em determinados momentos históricos.

Nesse período, segundo o mesmo autor, houve fortalecimento da filosofia dialética, contrapondo-se - e a contestando - à filosofia positivista. Os filósofos procuraram esclarecer a dinâmica da sociedade, analisando-a de forma totalizadora. Talvez tenha sido um dos momentos mais ricos e contraditórios no campo do pensamento por meio da observação e da análise da realidade na história. Moreira (20I0) comenta que as modificações e as conservações da sociedade, naquele momento, viviam em conflito.

Logo, para compreender a utilização do espaço, faz-se necessário o entendimento das correntes do pensamento geográfico. De acordo com Gomes (I996), ao final do século XIX, surge a corrente determinista, demonstrando os primeiros modelos de geografia como ciência. O determinismo trabalha com os casos sem fazer distinção e, ao estabelecer relações de causa e efeito, procura pensar sobre as categorias gerais, para, depois, chegar aos fatos. Defendida pelo geógrafo alemão Friedrich Ratzel, de acordo com Moraes (2002), essa corrente relata as influências que as condições naturais exercem sobre os seres humanos, ou seja, o meio natural determinaria o homem; os homens iriam organizar o espaço para garantir a manutenção da vida.

Andrade (I987, p. 54) reitera que esses dois pensadores alemães, Humboldt e Ritter, respondiam, em suas obras, ao desafio da sociedade europeia, na qual viviam, tanto na questão de domínio capitalista, quanto na formação da unidade da Alemanha, pois, naquele momento, o conhecimento de mundo e o aprofundamento das relações entre sociedade e natureza eram fundamentais para o "grupo de dominantes que aspiravam à união nacional, à unificação política [...] e à disputa pelo domínio do mundo extraeuropeu [...] e norte-americano” em um outro momento.

Os estudiosos posteriores a Humboldt e Ritter destacaram-se mais nos estudos específicos, como climatologia e geomorfologia, em vez de geografia geral. Moraes (2002, p. 52) explica que "um revigoramento do processo de sistematização da geografia vai ocorrer com as formulações de Friedrich Ratzel”, pois ele viveu o momento da constituição do real Estado Nacional Alemão em suas primeiras décadas e formulou uma concepção geográfica para atender as necessidades da nova sociedade. Andrade (I987, p. 54) coloca que o estudo de Ratzel estava voltado para a antropologia, afirmando que ele "encarou o homem como uma espécie animal e não como um elemento social", cuja evolução se daria por meio de adaptações ao meio natural. O autor afirma que Ratzel, em seus estudos, procurou entender as relações entre o homem e o meio, demonstrando o quanto os povos apresentam diferenças em vários sentidos. 
Segundo Moraes (2002), La Blache definiu a relação do homem com a natureza, na perspectiva da paisagem, como objeto da geografia. Assim, colocou o homem como um ser ativo, que sofre a influência do meio, porém, que atua sobre esse meio, transformando-o.

La Blache foi considerado um dos grandes responsáveis pela difusão da geografia humana, apesar de afirmar que a geografia não deveria estudar o homem, mas o meio em que ele vive, ou seja, deve estudar a "população não a sociedade; estudar os estabelecimentos humanos não as relações sociais; estudar as técnicas e os instrumentos de trabalho não o processo de produção" (MORAES, 2002, p. 72).

Percebe-se que o pensamento geográfico passou por grandes transformações, decorrentes das diferenças entre os pensadores de cada época. Logo é importante perceber que os geógrafos começaram a se preocupar em explicar a geografia com maior ênfase e detalhamento, aprofundando-se nos detalhes e procurando entender as maneiras de organização do homem no espaço a fim de elevar ao máximo a utilização dos recursos disponíveis.

Sentiram a necessidade, também, de expandir a sua área de conhecimento, buscando outras ciências para explicar a paisagem e compreender a realidade da região. Entre os geógrafos, havia uma confusão entre os conceitos, pois havia os que consideravam a geografia como uma ciência natural e não como uma ciência social, e os que diziam que a geografia era a ciência dos lugares e não do homem. Andrade (I987), porém, comenta que foi com os estudos de Paul Claval e Pierre George que a geografia se consolidou como uma ciência do social e do homem, e não somente uma ciência natural. Nesse sentido, a geografia, como ciência social e humana, tem a responsabilidade de observar e analisar a sociedade, bem como as próprias relações que influenciam no espaço produzido, além de explicar o porquê da utilização desse espaço.

Os movimentos de renovação da geografia iniciam suas manifestações a partir de I950. Daí por diante, muitas incertezas e questionamentos continuaram a surgir em vários pontos. De acordo com Moraes (2002), a geografia tradicional, em meados de I970, literalmente estava enterrada, ficando para um passado já de superações. Logo, um momento de críticas e novas propostas para a disciplina de geografia vai chegando de maneira sólida. Os geógrafos abrem espaços de debates para novas propostas e buscam soluções até então não discutidas. Esse é um momento de crise, de conflitos de pensamentos, porém benéfico, buscando na geografia tradicional propostas para uma disciplina mais aberta aos novos espaços.

As técnicas de análise de pesquisas da geografia tradicional não conseguem mais explicar os conceitos até então estabelecidos, pois uma mudança rápida e complexa apresenta-se nesse novo momento de organização do espaço. Faz-se necessária a busca por novas técnicas para estudar o espaço geográfico, adaptando os instrumentos para a coleta de dados de campo com maior precisão, fazendo uso dos computadores, das imagens de satélite e do uso do sensoriamento remoto.

Logo, foram destacados alguns pontos relevantes de crítica à geografia tradicional, como a indefinição do seu objeto de análise, abrindo espaço para outras áreas do conhecimento científico e a questão da generalização. A geografia sozinha buscava compreender o conjunto de acontecimentos de maneira resumida e "permaneceu nos estudos de singularidades" (MORAES, 2002, p. I06). Contudo, Moraes (2002) comenta 
que essa falta de outra forma de generalização agravou ainda mais a crise existencial da geografia tradicional, abrindo espaço para "dualidades que permearam toda a produção geográfica: Geografia Física e Geografia Humana, Geografia Geral e Geografia Regional, Geografia Sintética e Geografia Tópica” (MORAES, 2002, p. I06).

Souza et al. (2009) corroboram em seus estudos que a geografia tradicional é realmente marcada pela presença de dicotomias existentes entre a geografia física e a geografia humana, a geografia geral e a geografia regional, sendo a geografia física responsável pelos estudos naturais, e a geografia humana, responsável pelas atividades da população. Assim, o desenvolvimento das ciências da natureza se materializava com a geografia física.

O movimento de renovação representava uma dispersão, pois apresentava uma diversidade de métodos de interpretar e de se posicionar, buscando caminhos diferenciados para compreender essa área do conhecimento. A geografia renovada é bem diversificada e compreende concepções diferenciadas e que se dividem em geografia pragmática ${ }^{5}$ geografia crítica ${ }^{6}$.

Moraes (2002, p. I08) destaca dentro da geografia pragmática um estudo que se aproxima da psicologia, chamando de geografia da percepção ou comportamental. Essa geografia procurava compreender como as pessoas percebiam o espaço por elas ocupado, além de refletir sobre sua relação e ação ambiental com o meio em que vivem.

Nesse sentido, os pensadores dessa corrente buscam explicar e valorizar o território e os espaços vivenciados e a relação do comportamento humano com o meio. Logo, os estudos se baseiam nas relações do comportamento humano no espaço urbano, em "relação aos espaços de lazer; a influência das formas na produtividade de trabalho; a relação das sociedades com a natureza” (MORAES, 2002, p. I08).

Percebe-se que essa corrente pragmática é um instrumento da dominação burguesa, existindo um interesse do Estado capitalista na maximização dos lucros, na crescente acumulação de rendas, na manutenção e exploração do trabalho, mascarando assim as contradições da sociedade e regulando a ação do capital sobre o espaço terrestre.

A nova geografia e os paradigmas tradicionais, que surgem a partir de I970, segundo Christofoletti (I985), são fortemente questionados, surgindo então a geografia crítica, a qual o mesmo autor subdivide em geografia radical, humanística e idealista.

Para Moraes (2002), a denominação de geografia crítica vem de uma postura crítica radical em relação às correntes de pensamento geográfico existentes até então. A crítica diz respeito a um posicionamento em relação à realidade estabelecida. Os problemas sociais começam a aparecer, a renda concentra-se nas mãos de poucos privilegiados, as pessoas começam a procurar os centros maiores e migrar em

5 A geografia pragmática - também conhecida por nova geografia, geografia teorética ou quantitativa - faz uma crítica à falta de análise da geografia tradicional, por não analisar os seus fundamentos e nem tampouco a base social.

6 O pensamento crítico na geografia significou uma aproximação com os movimentos sociais, primando na busca por acesso a uma educação de qualidade, moradia, ampliação dos direitos civis e sociais, além do combate à pobreza, direito à terra, buscando, enfim, dialogar em diferentes espaços e gerando debates e conflitos de opiniões. 
busca de melhores condições. No entanto, esses espaços não possuíam condições de estrutura para acolher essas populações, causando problemas de ocupação do espaço.

Santos (I986) representa em sua obra Por uma geografia nova uma proposta geral para estudar o espaço geográfico e ainda retrata sobre a sua concepção do objeto geográfico. Procura dar uma resposta sobre o que é geografia e comenta que é importante dialogar sobre o espaço social e perceber a produção desse espaço como um elemento. Esse autor comenta que o espaço, além de ser social, faz parte da história, pois, ao mesmo tempo que reside nele, o homem se relaciona, produz e transforma o meio em que vive.

Contudo, o pensamento crítico na geografia significou uma aproximação com os movimentos sociais, primando na busca por acesso a educação de qualidade, a moradia, pela ampliação dos direitos civis e sociais, além do combate à pobreza, o direito à terra, enfim, a corrente crítica busca dialogar em diferentes espaços, gerando debates e conflitos de opiniões.

Assim sendo, devemos admitir que essas transformações no campo do conhecimento geográfico vêm colocando desafios para a formação não apenas do geógrafo pesquisador (técnico e planejador) como também para o geógrafo professor do ensino fundamental, médio e superior. A atual dinâmica das transformações pelas quais o mundo passa, com as novas tecnologias, com os novos recortes de espaço e tempo, com a predominância do instantâneo e do simultâneo, com as complexas interações entre as esferas do local e do global, afetando profundamente o cotidiano das pessoas, exige que a geografia procure caminhos teóricos e metodológicos capazes de interpretar e explicar essa realidade dinâmica.

\section{O ENSINO DE GEOGRAFIA PROPOSTO NOS DOCUMENTOS OFICIAIS E NA LITERATURA DIDÁTICA BRASILEIRA}

No território brasileiro, as primeiras intenções de formação em geografia surgiram através da Faculdade de Filosofia, Ciências e Letras da Universidade de São Paulo (USP) e do Departamento de Geografia em I934 (BRASIL, I998, p. I9). A disciplina de geografia passou a ser trabalhada nas escolas na década de I940 por professores licenciados, com ênfase na escola francesa de La Blache.

A geografia daquela época era marcada pelo esclarecimento objetivo e qualitativo da realidade da escola francesa, que tinha como objetivo aproximar as "relações do homem com a natureza de forma objetiva” (BRASIL, I998, p.I9). Nessa escola, embora se valorizasse o homem como sujeito histórico, estudava-se a relação entre homem e natureza sem levar em conta as relações sociais. Nesse sentido, a geografia estudava a população, mas não a sociedade, os utensílios de trabalho, desconsiderando os modos de produção, não possibilitando a discussão das relações essenciais à sociedade, afastando o homem de seu caráter social.

O ensino de geografia dessa época era centrado na descrição das paisagens, sem caracterizar o espaço ocupado pela sociedade e a organização dele. A maneira de ensinar era baseada em descrição e memorização das paisagens. Entre os anos de I940 a I970, a produção de livros didáticos reproduzia conceitos de aprendizagem defendidos pela geografia tradicional (BRASIL, I997). No período da ditadura militar, 
entre os anos de I964 e I985, a geografia e a história foram descaracterizadas pela Lei n. 5.692/7I e diluídas nos chamados estudos sociais.

Nesse contexto, a geografia acadêmica contemporânea busca por definições que tratem as relações particulares e individuais que os seres humanos em sociedade constituem com o espaço natural. Tais dimensões são organizadas pela experiência individual, marcadas pelos aspectos culturais da sociedade, que resultam em diferentes percepções da construção do espaço geográfico (BRASIL, I997). Com essa busca por explicações, surge a necessidade de ampliar os saberes geográficos com a intersecção de outras áreas do conhecimento, como a antropologia, a sociologia, a biologia e as ciências políticas. O que se queria, nessa época, era uma geografia que não estivesse vinculada a processos mnemônicos, restrita somente à descrição de paisagens e pautada em interpretar as questões políticas e econômicas do mundo. Mas que fosse uma geografia pautada nas relações socioculturais existentes nas paisagens, bem como os seus elementos físicos e biológicos interagindo entre si, formando, assim, um espaço geográfico.

As correntes de pensamento geográfico acabam condicionando a formação de professores de geografia, os conteúdos e as formas de seu ensino nas escolas brasileiras. Nesse sentido, o ensino de geografia desde a sua implementação vem sendo trabalhado muitas vezes de forma descontextualizada e distante da realidade dos estudantes.

Faz-se necessário ressaltar as abordagens didáticas e metodológicas utilizadas na literatura brasileira a fim de compreender e repensar posturas perante a formação para atuar nessa disciplina de tamanha importância na contemporaneidade, destacando que o foco principal do ensino de geografia é compreender o seu objeto de estudo, que é o espaço geográfico, entendendo-o como um produto histórico, um conjunto de objetos e de ações de determinado grupo, o qual possui maneiras diferenciadas de pensar, viver, sonhar, agir, enfim, de construir e transformar o espaço que ocupa.

O desafio da geografia escolar é fazer com que os estudantes identifiquem o espaço vivido através de experiências cotidianas relacionadas ao conteúdo estudado. Cabe ao professor possibilitar momentos para que a aprendizagem aconteça, observando esse espaço vivido de cada indivíduo, fazendo relações com o meio em que vive.

Os Parâmetros Curriculares Nacionais (PCNs) e a Base Nacional Comum Curricular (BNCC) são documentos orientadores para a prática profissional do professor que, além de auxiliarem na construção de uma educação geográfica, podem constituir-se no aspecto crítico de como fazer o ensino de geografia um conteúdo específico de uma matéria de ensino curricular, para compreender a sociedade a partir da análise espacial.

Diante deste contexto, o ensino de geografia pode servir para situar os sujeitos neste mundo de maneira que compreendam a espacialidade dos fenômenos e que os espaços resultam da história dos homens que vivem nos lugares, isto é, um espaço construído a partir dos interesses dos que ali vivem, como um jogo de forças a partir de relações de poder entre as pessoas e os grupos do lugar. Assim, a geografia crítica deve proporcionar um olhar analítico para que os educandos possam, além de 
entender que o que está singularizado no lugar possui elementos que o diferenciam de outro local, compreender, num sentido mais amplo e global, o mundo.

Logo, a geografia escolar tem um papel importante na construção de referências para os educandos; faz-se necessário que o profissional que se proponha a atuar como educador nessa área repense o que ensinar e como ensinar. Esse profissional deve compreender que a escola deve ser um lugar de encontro e confronto entre as diferentes formas de concepções e práticas cotidianas e científicas, pensando em uma educação próxima à realidade dos estudantes.

Ao considerar o estudante, que "é um ser histórico que traz consigo e em si uma história e um conhecimento adquirido na sua própria vivência” (CALLAI, 200I, p. I36), é necessário reconhecer a importância da análise do conhecimento do lugar em que ele vive em diferentes escalas, valorizando o seu cotidiano. Com isso, o estudo de geografia pode se tornar prazeroso, pois, quando relacionado com as experiências concretas vividas pelo estudante no seu espaço cotidiano, a sala de aula se torna um ambiente de vivências pedagógicas significativas, que contribuem para o desenvolvimento cognitivo. $O$ ensino de geografia cumpre, assim, sua verdadeira função, a de ir além do fornecimento de dados ou informações atuais, e passa a estabelecer relações sobre informações do mundo cotidiano, conforme afirma Martins (20II).

O município de Criciúma, de acordo com a regionalização do Instituto Brasileiro de Geografia e Estatística (IBGE), está localizado na Região Sul do Brasil, possui uma área de $210 \mathrm{~km}^{2}$, com uma altitude de $46 \mathrm{~m}$, localizada na latitude de $28^{\circ} 40^{\prime} 39^{\prime}$ 'S e uma longitude de $49^{\circ} 22^{\prime} \mathrm{II}$ ”.

Atualmente, Criciúma é o maior município do Sul Catarinense e um dos cinco maiores do estado catarinense, com uma população estimada em 2019 de 2I5.I86 habitantes. Por se tratar de um município com um número significativo de habitantes, tem instalados oito polos de instituições de ensino superior na modalidade de ensino a distância que ofertam vários cursos, dentre eles o curso licenciatura em geografia.

\section{CORRENTES DE PENSAMENTO GEOGRÁFICO: O QUE MOSTRAM OS DOCUMENTOS DAS IES PESQUISADAS}

Após o referencial teórico, com o propósito de verificar qual pensamento geográfico embasa a formação do professor de geografia em dois polos de ensino superior na modalidade de ensino a distância, localizados no município de Criciúma (SC), apresentamos os dados relativos à análise dos seguintes documentos: Diretrizes Curriculares Nacionais (DCNs), Proposta Pedagógica Curricular (PPC) e matriz curricular dos cursos.

Para compreender qual é o pensamento geográfico que se faz presente nos documentos analisados, foi definida a seguinte classificação: "presença”, "presença potencial" e "ausência". A classificação "presença" significa a existência do pensamento geográfico crítico no documento; "presença potencial" significa que o documento proporciona ao professor a oportunidade de incluir o pensamento 
geográfico crítico; “ausência" significa a não existência do pensamento geográfico crítico nos documentos analisados.

Por meio da Tabela I, em função da análise das DCNs para o ensino de geografia, cabe destacar que a presença da corrente de pensamento geográfico crítica, apareceu quatro vezes no documento. Da mesma forma, a presença potencial para uma corrente crítica de pensamento geográfico também apareceu por quatro vezes. Já as correntes de pensamento determinista e possibilista não houve presença e presença potencial e sim ausência no documento analisado.

\begin{tabular}{|c|c|c|c|c|c|}
\hline $\begin{array}{c}\text { Corrente de pensa- } \\
\text { mento geográfico }\end{array}$ & Presença & $\begin{array}{c}\text { Presença } \\
\text { potencial }\end{array}$ & Ausência & $\begin{array}{c}\text { Total de } \\
\text { ocorrências }\end{array}$ & $\begin{array}{c}\text { Total de } \\
\text { documentos }\end{array}$ \\
\hline Geografia determinista & 0 & 0 & 4 & 4 & I \\
\hline Geografia possibilista & 0 & 0 & 4 & 4 & I \\
\hline Geografia crítica & 4 & 4 & 0 & 8 & I \\
\hline
\end{tabular}

Tabela I - Análise da corrente de pensamento geográfico contida nas DCNs. Elaboração dos Autores com base em Bardin (2009)

Diante das análises realizadas em busca do pensamento geográfico presente nas DCNs dos cursos de geografia, percebe-se que o pensamento geográfico crítico se faz presente, pois a geografia é uma área do conhecimento que vem, ao longo dos anos, consolidando teorias científicas na busca por compreender e explicar as diferentes interações entre a sociedade e o meio natural, como se inter-relacionam.

Atualmente, no mundo em que vivemos, percebe-se a sua constante transformação, e é através dessa movimentação que surgem novos espaços apresentando relações complexas de interação em âmbito local e global, que vão se refletir no dia a dia da população, fazendo com que o campo da geografia busque por métodos e teorias com condições suficientes para auxiliar na compreensão dessa realidade.

Os colegiados dos cursos de geografia devem buscar por metodologias que possibilitem a "liberdade da crítica" e que consigam se desvincular do livro didático como "cartilha" (BRASIL, 200I), pois o objeto de estudo é o espaço geográfico onde tudo acontece, considerando o rigor científico dessa área do conhecimento.

Percebe-se nas DCNs de geografia a tendência do pensamento geográfico para uma criticidade, possibilitando aos estudantes de graduação criar e estabelecer situações de reflexão sobre o meio em que vivem para poderem atuar nas escolas, fazendo uso de diferentes metodologias e não somente o livro didático.

$\mathrm{Na}$ Tabela 2 apresentamos a análise das concepções de ensino contidas nos projetos pedagógicos dos cursos de geografia pesquisados, apresentados como A e B. 


\begin{tabular}{|c|c|c|c|c|c|}
\hline \multirow{2}{*}{$\begin{array}{c}\text { Concepções } \\
\text { de ensino }\end{array}$} & Presença & $\begin{array}{c}\text { Presença } \\
\text { potencial }\end{array}$ & Ausência & $\begin{array}{c}\text { Total de } \\
\text { ocorrências }\end{array}$ & $\begin{array}{c}\text { Total de } \\
\text { documentos }\end{array}$ \\
\cline { 2 - 6 } & A/B & A/B & A/B & A/B & A/B \\
\hline Tradicional & 0-0 & $0-0$ & $4-4$ & $4-4$ & 2 \\
\hline Tecnicista & $0-0$ & $0-0$ & $4-4$ & $4-4$ & 2 \\
\hline Histórico- & $4-4$ & $4-4$ & 0 & $8-8$ & 2 \\
\hline -crítica & & & & & \\
\hline
\end{tabular}

Tabela 2 - As concepções de ensino geográfico contidas nos

PPCs dos cursos. Elaboração dos Autores, 2020

Após análise dos documentos, fica evidenciado que os dois cursos apresentam em seus projetos pedagógicos todos os itens estabelecidos pelas DCNs do curso de licenciatura em geografia, sendo que a formação inicial deve ter como finalidade preparar o estudante para a docência em geografia.

As palavras temas presentes nos documentos analisados - como pensamento crítico, preparação do estudante para atuar em sociedade, debates, troca de experiências e interdisciplinaridade - sinalizam, nos dois projetos pedagógicos dos cursos de geografia, a presença de uma concepção de pensamento geográfico crítico.

Moraes (2002) destaca a denominação de geografia crítica, aquela que vem de uma postura crítica radical em relação às correntes de pensamento geográfico existentes até então, como o determinismo e o possibilismo. Logo, busca-se uma transformação da realidade social, resgatando o objeto de estudo como uma "arma" frente a esse processo. Assim, luta-se por uma geografia de caráter militante, que busque uma sociedade justa e igualitária, considerando as questões geográficas como um instrumento para libertar o ser humano da ausência de conhecimentos.

Santos (I986) destaca ainda que o espaço, além de ser social, faz parte da história, pois, ao mesmo tempo que reside nele, o homem se relaciona com o meio em que vive, produzindo-o e o transformando.

O pensamento crítico na geografia significou uma aproximação com os movimentos sociais, primando pela busca ao acesso a uma educação de qualidade, a moradia, a ampliação dos direitos civis e sociais, além do combate à pobreza, o direito à terra, buscando, enfim, dialogar em diferentes espaços, gerando debates e conflitos de opiniões. Nesse sentido, essa abordagem diz respeito a um posicionamento em relação à realidade estabelecida, constatando-se pela análise dos documentos que ambos apresentam uma abordagem histórico-crítica, apresentando total de oito (8) ocorrências da Tabela 2.

Na Tabela 3, apresentamse os dados da corrente de pensamento geográfico contida na grade curricular dos cursos analisados.

De maneira geral, no documento das instituições verificadas, consta que o futuro profissional deverá estar preparado para atuar com qualidade para o exercício da docência na sua área de conhecimento, apresentando-se como um profissional capacitado para lidar com as situações no espaço escolar, proporcionando aos 
estudantes conhecimentos científicos, práticos e pautados em uma corrente de pensamento crítica.

O documento preconiza que a implementação da iniciação científica do curso de licenciatura em geografia é uma forma pela qual é desenvolvida a linha de pensamento crítica, a qual possibilita ao estudante debater e estar em contato com as teorias da disciplina de geografia. $\mathrm{O}$ documento retrata a concepção do pensamento geográfico crítico, estabelecido por Moraes (2002), que diz respeito a um posicionamento em relação à realidade estabelecida, possibilitando uma abertura para pensar e buscar posicionamentos e resoluções de possíveis problemas.

\begin{tabular}{|c|c|c|c|c|c|}
\hline \multicolumn{7}{|c|}{ GRADE CURRICULAR } \\
\hline \multirow{2}{*}{$\begin{array}{c}\text { Corrente de pensa- } \\
\text { mento geográfico }\end{array}$} & Presença & $\begin{array}{c}\text { Presença } \\
\text { potencial }\end{array}$ & Ausência & $\begin{array}{c}\text { Total de } \\
\text { ocorrências }\end{array}$ & $\begin{array}{c}\text { Total de } \\
\text { documentos }\end{array}$ \\
\cline { 2 - 6 } & $\mathrm{A} / \mathrm{B}$ & $\mathrm{A} / \mathrm{B}$ & $\mathrm{A} / \mathrm{B}$ & $\mathrm{A} / \mathrm{B}$ & $\mathrm{A} / \mathrm{B}$ \\
\hline Determinista & 0-0 & $0-0$ & $4-4$ & $4-4$ & 2 \\
\hline Possibilista & $0-0$ & $0-0$ & $4-4$ & $4-4$ & 2 \\
\hline Crítica & $4-4$ & $4-4$ & 0 & $8-8$ & 2 \\
\hline
\end{tabular}

Tabela 3 - Corrente de pensamento geográfico contida na grade curricular. Elaboração dos Autores, 2020

Ao verificar os documentos das instituições pesquisadas, percebeu-se que, de acordo com as palavras-temas (construção da cidadania; formação pedagógica; compreensão do espaço geográfico e interdisciplinaridade), a ocorrência pela presença e presença potencial é de quatro nos dois documentos analisados. Percebe-se que isso tem a ver com a amplitude da disciplina de geografia, possibilitando nessa área do conhecimento desenvolver com os estudantes a interdisciplinaridade, pois, de acordo com Callai (2013), a geografia é uma disciplina curricular que contribui muito com a produção de instrumentos intelectuais para compreender o mundo e entender as pessoas como sujeitos deste mundo.

Uma questão presente nas duas instituições analisadas na modalidade a distância é que a graduação deve proporcionar aos estudantes a possibilidade de, além de conhecerem os conteúdos das disciplinas, realizarem a interação entre as áreas do saber. Percebe-se, no documento, que o estágio curricular é descrito como um componente obrigatório para ser cumprido legalmente e que necessita de planejamento e preparação dos estudantes que frequentam o ensino regular da instituição de nível superior. Observa-se, aqui, uma articulação entre a teoria e a prática, momento este que coloca o estudante a pensar sobre a realidade do espaço escolar, estabelecendo um início para as atividades de estágio em um movimento entre o saber e o fazer.

Entendendo que o estágio obrigatório é um componente que vai articular a relação entre a teoria e a prática, Pimenta (2002) destaca que o estágio obrigatório 
constitui uma reflexão sobre a realidade educacional e a partir dessa realidade o conhecimento teórico faz parte como elemento de investigação e pesquisa para as atividades práticas de docência.

Pimenta (2002) afirma que o estágio obrigatório é uma disciplina teórica que vai se aproximar às práticas no espaço escolar, o que caracteriza uma discordância em relação aos documentos analisados nas duas instituições, que apresentam o estágio obrigatório como mais uma disciplina prática, que proporciona aos estudantes a oportunidade de observar na prática escolar e relacionar com a teoria estudada.

Logo, faltam elementos nos documentos analisados para compreender melhor a organização do estágio curricular obrigatório e, assim, perceber qual é a concepção de pensamento geográfico que está sendo desenvolvida pelo estudante em seu momento de prática pedagógica.

\section{CONSIDERAÇõES FINAIS}

Ao verificar os documentos das DCNs de licenciatura em geografia, os PPCs e a matriz dos dois cursos, foi possível perceber que estão em consonância com a legislação e bem atualizados no que se refere ao currículo e à organização das disciplinas apresentadas na matriz curricular.

Com a análise da corrente de pensamento geográfico presente nas Diretrizes Curriculares Nacionais, foi possível perceber e refletir que a geografia deve assumir o compromisso de buscar descobrir o conhecimento complexo que justifica a existência do seu objeto de estudo, que é o espaço geográfico dentro dos currículos escolares, visto que o documento aponta para diferentes situações de compreensão desse espaço.

Quanto à análise dos PPCs dos dois cursos, observou-se que cada instituição se organiza de maneira diferenciada, porém as duas pautadas nas normas da legislação estipulada pelo MEC, principalmente em relação às DCNs.

Percebe-se que na elaboração dos documentos dos cursos houve atenção aos documentos legais, uma vez que são eles que normatizam a implementação de possíveis modificações nos currículos, de forma a superar a cultura da "cartilha" sem abrir mão do rigor científico e metodológico que se deve ter perante a disciplina de geografia. As duas instituições pesquisadas formam professores de geografia, ficando claro que os primam pela autonomia, desenvolvimento da criticidade, competências e habilidades para que o estudante ao longo do curso possa ir se aperfeiçoando e interagindo com teorias e práticas. No entanto, não se tem clareza, a partir do estudo dos documentos, como essas questões são realizadas na modalidade a distância.

Percebe-se ainda, ao verificar os PPCs, que existe a preocupação dos colegiados dos cursos em atender esse novo momento da sociedade frente às inovações e o compromisso em formar profissionais com capacidade suficiente para exercer sua cidadania e ser um agente de transformação da sociedade.

$\mathrm{Na}$ análise das matrizes curriculares, foi possível perceber que as disciplinas e atividades propõem novos desafios, trabalhando com diferentes metodologias e estratégias diferenciadas, desenvolvendo nos estudantes habilidades e competências 
para que a prática de sala de aula esteja alicerçada e com embasamento teórico, de modo que o curso possa realmente resgatar a consciência cidadã de seus estudantes e que eles, após a formação inicial, consigam em seus espaços de trabalho desenvolver atividades que busquem a formação de cidadãos reflexivos, atuantes e com criticidade para transformar o espaço geográfico em que vivem com conhecimento e sabedoria.

No entanto, cabe a reflexão: será que a geografia é capaz de contribuir com as tensões, os conflitos e as representações sociais que aparecem dentro do espaço escolar como um ponto de encontro e (des)encontro de histórias, de geografias de indivíduos que pensam e agem de modo diferente um do outro? Será que esses futuros profissionais frente ao mundo atual terão condições de perceber a corrente de pensamento geográfico que perpassa por entre os conteúdos trabalhados? São alguns questionamentos que ficaram no processo de pesquisa.

Nas instituições de ensino superior pesquisadas, ficou evidenciado pelos documentos analisados que a corrente que embasa a formação do professor de licenciatura em geografia é a corrente crítica, no entanto, uma pesquisa que abarcasse os egressos e o Núcleo Docente Estruturante (NDE) dos referidos cursos talvez pudesse ratificar a predominância dessa corrente ou apresentar novas questões para pesquisa.

Este estudo contribuiu para muitas outras interrogações que surgem a cada leitura e análise que se realiza, pois, se as instituições de ensino superior, em seus documentos, estão pautadas conforme a legislação, estão organizadas em seus currículos pedagógicos primando pela formação crítica, será que esses futuros profissionais conhecem o espaço geográfico no qual estão dispostos a trabalhar?

Os referenciais teórico-metodológicos de maior destaque na literatura sobre o ensino de geografia são os PCNs e a BNCC. No entanto, cabe outra reflexão: será que as instituições de ensino superior na modalidade de ensino à distância, que formam professores de geografia para atuarem nas escolas da região, conhecem e fazem uso desse material, garantindo assim os aportes teóricos relacionando a prática no cotidiano escolar, fazendo com que essa disciplina escolar possa refletir, analisar, investigar, enfim, alfabetizar para uma educação geográfica e compreender a corrente de pensamento por ela embasada?

Muitos são os desafios para repensar a prática pedagógica, pois ensinar geografia é muito mais que trabalhar com conteúdo desconectados ou repetir conceitos prontos, é conseguir articular o conhecimento geográfico nos seus aspectos físico e humano, relacionando-os, para que a geografia na escola seja realmente significativa e faça relação com a teoria estudada. 


\title{
SOBRE OS AUTORES
}

\author{
ANDRÉA RABELO MARCELINO é professora e \\ coordenadora do Curso de Geografia da Universidade \\ do Extremo Sul Catarinense (UNESC). \\ armarcelino@unesc.net \\ https://orcid.org/0000-0002-I936-4I4I
}

GILDO VOLPATO é professor permanente do Programa de Pós-Graduação em Educação da Universidade do Extremo Sul Catarinense (PPGE/ Unesc). giv@unesc.net https://orcid.org/o0oo-000I-9167-7559

\section{REFERÊNCIAS}

ANDRADE, Manuel Correia de. Geografia: ciência da sociedade. São Paulo: Atlas, I987.

ANDRADE, Maria Margarida de. Introdução à metodologia do trabalho científico: elaboração de trabalho na graduação. Io. ed. São Paulo: Atlas, 2010.

ARCASSA, Wesley de Souza. Friedrich Ratzel: a importância de um clássico. Geographia Opportuno Tempore, v. 3, n. I, 20I7, p. 98-II5. Disponível em: http://www.uel.br/revistas/uel//index.php/Geographia/ article/view/3I840. Acesso em: 22 de janeiro de 2019.

BARDIN, Laurence. Análise de conteúdo. Lisboa: Edições 70, 2009.

BESSI, Meri Loudes. Região: uma (re)visão historiográfica - da gênese aos novos paradigmas. Santa Maria: Ed. da UFSM, 2004.

BOGDAN, Robert; BIKLEN, Sari. Características da investigação qualitativa. In: BOGDAN, Robert; BIKLEN, Sari. Investigação qualitativa em educação: uma introdução à teoria e aos métodos. Porto: Porto Editora, I994, p. 47-5I. (Coleção Ciências da Educação I2).

BRASIL. Presidência da República. Casa Civil. Subchefia para Assuntos Jurídicos. Lei 9.394, de 20 de dezembro 1996. Estabelece as diretrizes e bases da educação nacional. Disponível em: http://www. planalto.gov.br/ccivil_03/leis/L9394.htm. Acesso em: 22 jan. 2019.

BRASIL. Secretaria de Educação Fundamental. Parâmetros curriculares nacionais: história, geografial Secretaria de Educação Fundamental. Brasília: MEC/SEF,I997. Disponível em: http://portal.mec.gov. br/seb/arquivos/pdf/livroo5I.pdf. Acesso em: 22 jan. 2019.

BRASIL. Secretaria de Educação Fundamental. Parâmetros curriculares nacionais: geografia. Secretaria de Educação Fundamental. Brasília: MEC/SEF, I998. Disponível em: http://portal.mec.gov.br/seb/ arquivos/pdf/geografia.pdf. Acesso em: 22 jan. 2019.

BRASIL. Ministério da Educação. Conselho Nacional de Educação/Câmara Superior de Educação. Parecer CNE/CES 492/200I - homologado. Diretrizes Curriculares Nacionais dos cursos de Filosofia, História, Geografia, Serviço Social, Comunicação Social, Ciências Sociais, Letras, Biblioteconomia, 
Arquivologia e Museologia. Brasília: MEC/CNE, 200I. Disponível em: http://portal.mec.gov.br/cne/ arquivos/pdf/CESo492.pdf. Acesso em: 9 mar. 2019.

CALLAI, Helena Copetti. A formação do profissional da geografia: o professor. Ijuí: Ed. Unijuí, 2013.

CHRISTOFOLETTI, Antonio. Perspectivas da geografia. 2. ed. São Paulo: Difel, I985.

FERREIRA, Conceição Coelho; SIMÕES, Natércia Neves. A evolução do pensamento geográfico. 7. ed. Lisboa: Gradiva, I992.

GIL, Antonio Carlos. Técnicas de pesquisa em economia e elaboração de monografias. 4. ed. São Paulo: Atlas, 2002.

GIL, Antonio Carlos. Como elaborar projetos de pesquisa. 4. ed. São Paulo: Atlas, 2008.

GOMES, Paulo César da Costa. Geografia e modernidade. Rio de Janeiro: Bertrand Brasil, I996.

MARCELINO, Andréa Rabelo. O pensamento geográfico na formação do professor de geografia: um estudo em dois cursos de licenciatura. Dissertação (Mestrado). Programa de Pós-Graduação em Educação, Universidade do Extremo Sul Catarinense, Criciúma, 2019.

MARTINS, G. A.; THEÓPHILO, C. R. Metodologia da investigação científica para ciências sociais aplicadas. 2. ed. São Paulo: Atlas, 2009.

MEDEIROS, Lucy Satyro de. O currículo escolar de geografia e a construção do conhecimento: um olhar para a prática pedagógica do professor de Geografia. Dissertação (Mestrado). Universidade Federal da Paraíba, João Pessoa. 20Io. Disponível em: http://www.geociencias.ufpb.br/posgrad/dissertacoes. html. Acesso em: II jan. 20I9.

MORAES, Antônio Carlos Robert. Geografia: pequena história crítica. São Paulo: Hucitec, 2002.

MOREIRA, Ruy. O que é geografia. São Paulo: Brasiliense, I994.

MOREIRA, Ruy. O pensamento geográfico brasileiro: as matrizes clássicas originárias. São Paulo: Contexto, 2010.

NOGUEIRA, Valdir; CARNEIRO, Sônia Maria Marchiorato. Educação geográfica e a formação da consciência espacial cidadã. Curitiba: ed. UFPR, 2013.

PEREIRA, Raquel Maria Fontes do Amaral. Da geografia que se ensina à gênese da geografia moderna. 4. ed. ver. Florianópolis: Ed. da UFSC, 2009. Disponível em: https://repositorio.ufsc.br/handle/123456789/75444. Acesso em: 9 mar. 2019.

PIMENTA, Selma Garrido. Estágio e docência. São Paulo: Cortez, 2002.

SÁ-SILVA, Jackson Ronie; ALMEIDA, Cristóvão Domingos, GUINDANI, Joel Felipe. Pesquisa documental: pistas teóricas e metodológicas. Revista Brasileira de História e Ciências Sociais, n. I, julho de 20I9, p. I-I5. Disponível em: http://www.scielo.br/scielo.php?script=sci_nlinks\&ref=0002I5\&pid=So03476I220I400040000400033\&lng=pt. Acesso em: 9 mar. 2019.

SANTOS, Milton. Espaço e método. São Paulo: Nobel, I985.

SANTOS, Milton. Por uma geografia nova: da crítica da geografia a uma geografia crítica. 3. ed. São Paulo: Hucitec, I986.

SEVERINO, Antônio Joaquim. Metodologia do trabalho científico. 23. ed. rev. e atual. São Paulo: Cortez, 2007. SOUZA, C. G. et al. As principais correntes do pensamento geográfico: uma breve discussão da categoria de análise de lugar. Enciclopédia Biosfera, Centro Científico Conhecer, Goiânia, n. 7, 2009. Universidade Estadual do Sudoeste da Bahia. Disponível em: http://www.conhecer.org.br/enciclop/2009/as\%20 principais.pdf. Acesso em: 9 mar. 2019.

TRIVIÑOS, A. N. S. Introdução à pesquisa em ciências sociais: a pesquisa qualitativa em educação. São Paulo: Atlas, I987.

VESENTINI, José William (org.). O ensino de geografia no século XXI. 7. ed. Campinas: Papirus, 2013. 